MS37-02

\section{New insights in mechanochemical processes using real-time in situ investigations}

Franziska Emmerling ${ }^{1}$, Irina Akhmetova ${ }^{1}$, Hannes Kul ${ }^{1}$, Sebastian Haferkamp $^{1}$

1. Analytical Chemistry Federal Institute for Materials Research and Testing, Berlin, Germany

email: franziska.emmerling@bam.de

Mechanochemistry is a fast and efficient method applicable for the synthesis of new organic ${ }^{[1]}$, metal-organic ${ }^{[2]}$, and inorganic $^{[3]}$ compounds. The direct monitoring of milling reactions is still challenging. The underlying reaction mechanisms remain often unclear. In the last years, have established a tandem in situ approach for investigating mechanochemical reactions using time-resolved in situ XRD coupled with Raman spectroscopy. ${ }^{[4]}$ Here, we present an in situ coupling of synchrotron XRD, Raman spectroscopy, and thermography allowing the observation of mechanochemical reactions in real time. ${ }^{[5]}$ Information on the crystalline, molecular, and temperature state of the materials during grinding could be collected. The chemical composition of the reaction mixture was found to be directly correlated with changes in the temperature profile of the reaction. Furthermore, the presented setup allows the detection of crystalline, amorphous, eutectic as well as liquid intermediates. The resulting deeper kinetic and thermodynamic understanding of milling processes is the key for future optimization of mechanochemical syntheses.

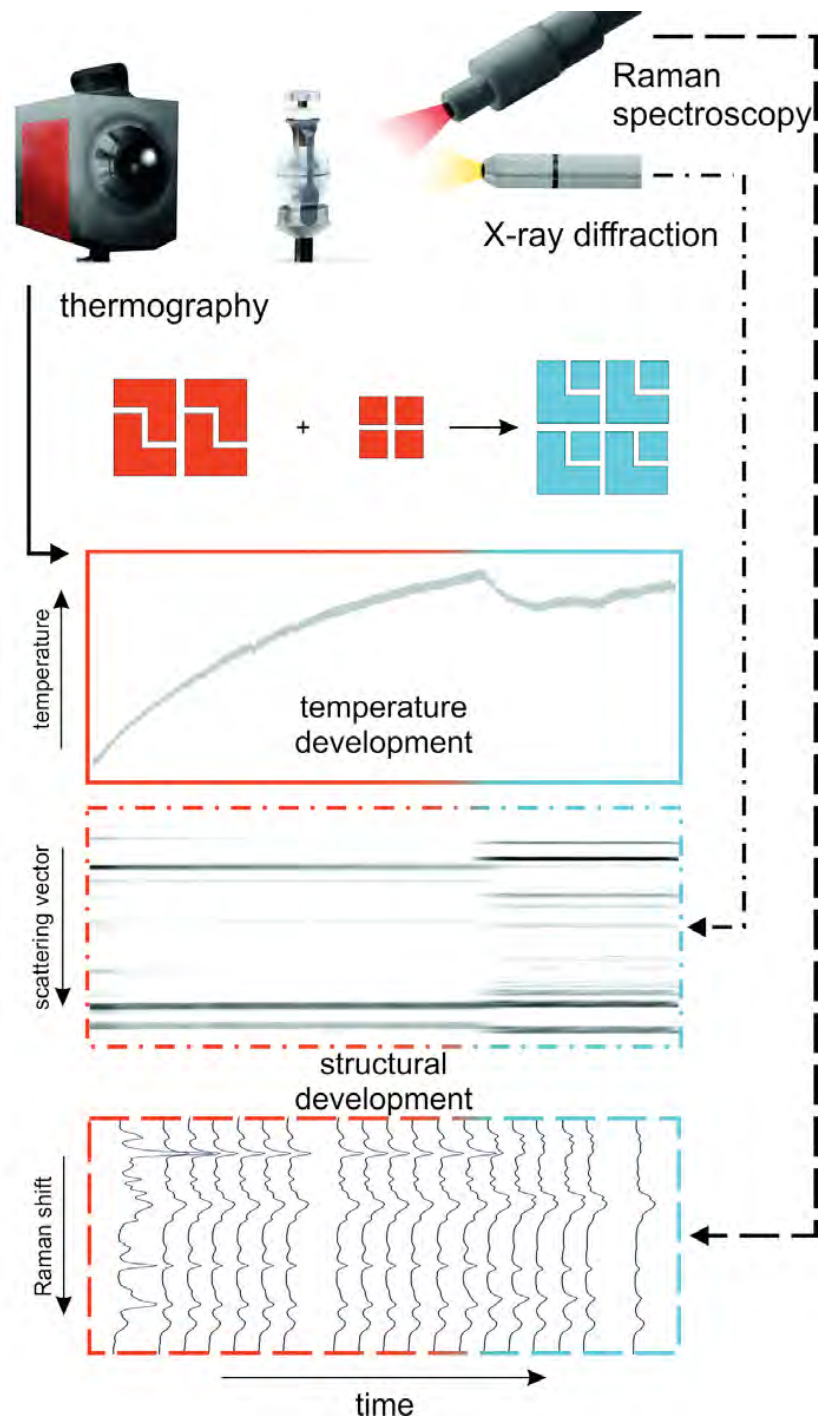

References:

[1] S. L. James, C. J. Adams, C. Bolm, D. Braga, P. Collier, T. Friscic, F. Grepioni, K. D. M. Harris, G. Hyett, W. Jones, A. Krebs, J. Mack, L. Maini, A. G. Orpen, I. P. Parkin, W. C. Shearouse, J. W. Steed, D. C. Waddell, Chemical Society Reviews 2012, 41, 413-447. [2] A. L. Garay, A. Pichon, S. L. James, Chemical Society Reviews 2007, 36, 846-855.

[3] P. Balaz, M. Achimovicova, M. Balaz, P. Billik, Z. CherkezovaZheleva, J. M. Criado, F. Delogu, E. Dutkova, E. Gaffet, F. J.

Gotor, R. Kumar, I. Mitov, T. Rojac, M. Senna, A. Streletskii, K. Wieczorek-Ciurowa, Chem Soc Rev 2013, 42, 7571-7637.

[4] L. Batzdorf, F. Fischer, M. Wilke, K. J. Wenzel, F. Emmerling, Angew Chem Int Ed Engl 2015, 54, 1799-1802.

[5] H. Kulla, Akhmetova, I. , Haferkamp, S. , Röllig, M. , Maierhofer, C. , Rademann, K., Emmerling, F., Angew. Chem. Int. Ed. 2018, doi:10.1002/anie.201800147.

Keywords: in situ, XRD, Raman spectroscopy 